\title{
PÄEVATEEMA
}

\section{PILK EESTI KIRJAKEELE KORRALDAMISE SAJANDILE JA TÄNAPÄEVALE}

Eesti kirjakeel, mis suures osas rajaneb põhjamurretel, tegi keelekorraldajate pingutusel XX sajandil läbi märkimisväärse kohandamise selleks, et olla kõigis valdkondades sobiv kompromislik kirjavahend. Erinevalt rahvuslikest liikumistest muudes maades on võor $r$ laenud olnud sallitud, osaliselt ajendatuna soovist hôlbustada ligipääsu Lääne-Euroopa kultuurile. Selle tulemusel tekkinud normingud on aga eestlasi üldiselt sundinud abi otsima mahukast õigekeelsuskäsiraamatust, et teada õigekirjutus- ja morfoloogianorme. ${ }^{1}$

Kas eesti keel on tõesti üle normitud või on eestlased liiga norminguusku? Niisuguse mulje jätab tuntud Ameerika fonoloog ja eesti keele lühigrammatika koostanud Robert T. Harms (1932-2016) oma muidu lakoonilises ülevaates eesti keele kohta maailma keeltele pühendatud teatmeteoses.

2018. aasta sügisel möödus sada aastat esimese ÕS-i ilmumisest. Raamatu täpne pealkiri oli „Eesti keele õigekirjutuse-sõnaraamat” ja väljaandja Eesti Kirjanduse Selts. Selle eellugu on mõistagi pikem: nimelt 1905. aasta revolutsiooni järel hakati aastast 1906 lubama eestikeelse erahariduse andmist ja tekkis suur vajadus eestikeelse õppekirjanduse järele. ${ }^{2}$ Et Eesti jagunes

1 R. T. Harms, Estonian. - Concise Encyclopedia of Languages of the World. Toim K. Brown, S. Ogilvie. Oxford: Elsevier Ltd., 2009, lk 377-378.

${ }^{2}$ Põhiallikad ajaloo käsitlemisel on olnud: E. Ahven, Eesti kirjakeele arenemine aastail 1900-1917. (Eesti NSV Teaduste Akadeemia. Keele ja Kirjanduse Instituudi kahe kubermangu vahel, tekkisid kirjakeelt korraldavad kogud algul eraldi: augustis 1906 asutati Tallinnas Eestimaa Rahvahariduse Selts, mille juurde sama aasta 10. detsembril moodustati kirjandusosakond. See hakkas arutama kirjaviisi küsimusi, korraldades 1907. aastal keelekoosolekuid, ning kavatses kokku kutsuda keeletundjate kongressi. Tegevad olid Ernst Peterson-Särgava, Johannes Voldemar Veski jt. Tartus asutati aastal 1907 Eesti Kirjanduse Selts (EKS), mille juurde 6. augustil loodi kirjaviisikomisjon, kus olid tegevad Kaarel Leetberg, Jaan Jõgever, Hans Einer, Karl August Hermann, Juhan Kurrik jt; hiljem nimetati see keeletoimkonnaks. Need kaks kogu võistlesid algul mingil määral omavahel, kuid suutsid siiski kokku leppida, korraldades aastatel 1908-1911 Tapal, Tallinnas ja Tartus neli keelekonverentsi, mis sõnastasid otsused tollal kõige enam vaieldud teemadel: kas pea või pä̈̈, kas sõna algusse $h$ kirjutada või mitte, kuidas kirjutada $k i$-liidet jne.

Koostöömeeles sündis ka normiva sõnaraamatu idee. EKS-i sõnaraamatu kava seati kokku aastal 1908, alustati 1910 või 1911. See oli üks seni väheseid sõnaraamatuid, mis pandi kokku täiesti kollektiivselt, kokku 153 ,istangul”, töö sai enamjaolt valmis 1916 ja põhiline teksti kokkukirjutaja oli Jaan Tammemägi.

Sõnaraamatu koostajatel oli kadestamisväärne ettenägemisvõime, sest

uurimused IV.) Tallinn: Eesti Riiklik Kirjastus, 1958; T. Erelt, Eesti keelekorraldus. Tallinn: Eesti Keele Sihtasutus, 2002. 
see sai valmis just õigel ajal, õieti veel isegi enne seda. 1918. aastal, veel Saksa okupatsiooni ajal trükki antud sõnaraamatut hakati reklaamima septembris $^{3}$ ja kaks kuud hiljem, 11. novembril 1918, kui Eesti Ajutine Valitsus faktilise võimu üle võttis, oli kirjakeele normi allikas kohe võtta. Ametlik keelekasutus vajab normi või autoriteeti. On tähelepanuväärne, et veel Vabadussõja ajal pidas sõjaminister oma päevakäskudes, arvatavasti 1919 . aasta I poolel, vajalikuks kaht keeleteemalist otsust: nr 36 (õigekirjutuse alal Eesti Kirjanduse Seltsi sõnaraamat juhtnööriks võtta) ja nr 51 (ametlikud dokumendid tuleb eesti keeles välja anda; tõlge võib juures olla) ${ }^{4}$. Ka haridusministeerium võttis õpetuses aluseks selle sõnaraamatu, nagu näitavad 1921. aasta mais kinnitatud algkooli õppe- ja tunnikavad ${ }^{5}$. Raamatu menu näitab asjaolu, et 1921. aastal ilmunud esimeses Raamatu Teatajas on märgitud: trükk otsas.

Et pärast Eesti Vabariigi väljakuulutamist lõpetas Eestimaa Rahvahariduse Selts tegevuse ning tegutsema jäi vaid Eesti Kirjanduse Selts, siis vaadati edaspidi EKS-i keeletoimkonna kui autoriteedi peale. Sellega paralleelselt andis keelesoovitusi ka 1920. aastal loodud Emakeele Seltsi juhatus, kes vastas keeleteemalistele küsimustele, eriti nimesid puudutavatele. Põhiliseks jäi siiski keeletoimkond, kelle otsused avaldati ajakirjades Eesti Keel ja Eesti Kirjandus.

Kaks asjaolu on sellest ajast jäänud eesti keelekorraldusele organisatoorses mõttes iseloomulikuks: keelekorraldusega tegeleb asjatundjate kogu, mitte riigiasutus, ja tulemused kajastuvad sõnaraamatus, mille traditsiooniliseks

\footnotetext{
${ }^{3}$ Näiteks ilmus kuulutus ajalehes Maaliit 9. IX 1918.

4 Tähestik Sõjaministri päevakäskudes 1918-1919 a. ilmunud seadustele, määrustele ja korraldustele. [Tallinn: Eesti Sõjaministeerium], 1920.

${ }^{5}$ Algkooli õppe- ja tunnikavad. Tallinn: Haridusministeerium, 1921.
}

nimetuseks kujunes teisest trükist (1925) alates õigekeelsussõnaraamat. Riik on kogu selle aja usaldanud keelenormingute väljatöötamise kollektiivse otsustuskogu kätte; ei meenu ühtegi keelekorralduslikku otsust, mille oleks teinud Eestis riigiasutus. Lätis näiteks kehtestas riik 1919 iseseisvudes läti uue kirjaviisi - mille oli välja töötanud Läti Seltsi ortograafiakomisjon 1908 ja 1940. aastal otsustas valitsus muuta ladina-kreeka päritoluga võõrsõnade kirjutusviisi, kaotades neist pikad vokaalid, mida antiigiihalejad olid täpsema algupära jäljendamiseks ette kirjutanud. Ka Nõukogude Venemaal kehtestas hariduse rahvakomissar Anatoli Lunatšarski detsembris 1917 parandatud kirjaviisi, ilma jättide ja kõvendusmärkideta. Eestis, tõsi, oli uus kirjaviis juba 1870. aastatel juurdunud tänu Eesti Kirjameeste Seltsi tegevusele. On kuulda olnud väiteid, et Eesti enamlased ei leidnud hiljem eesti kirjaviisis midagi muud parandamisväärset kui kaotada sõnaalguse $h$, mida niigi ei hääldata, aga olid sellestki sunnitud loobuma.

1920.-1930. aastatel riik keelekorraldusse ei sekkunud, kuid tunnustas selle tulemusi ja ilmselt ka toetas seda tegevust rahaliselt. Oli riigi ülesehitamise aeg, ümber tuli korraldada terve haridussüsteem, arendada terminoloogiat jne. Tagantjärele mõeldes oli imetlusväärne see, et kahekümne aastaga jõuti eesti keelele anda nii tugev vundament, mis pidas vastu veel 50 aastat Nõukogude aega. Kui see praegu tundub enesestmõistetav, siis võrreldagu Eesti riigi ja eesti keele saatust Nõukogude Liidu vabariikidega, mis ei olnud vahepeal iseseisvad ja kus keeled olid eriti Nõukogude lõpuperioodil pigem dekoratiivse staatusega. Faktiliselt neid asjaajamises ei kasutatud.

Edasine eesti keelekorralduse ajalugu näeb korralduslikust küljest lühidalt välja järgmine. Eesti Kirjanduse Selts likvideeriti 1940. aastal ja seetõttu kadus ka keeletoimkond. Vahest mõtteliselt vaadati normiküsimustes seejärel 
Eesti Riikliku Kirjastuse poole, kus moodustati oma keeletoimkond, ent selle otsustest on suhteliselt vähe teada, vaid mõned ülevaated: näiteks revideeriti vene nimede transkribeerimise juhiseid. Kui 1947. aastal loodi Keele ja Kirjanduse Instituut, siis hakati normiküsimustes pöörduma selle asutuse, eeskätt sõnaraamatute sektori poole. Mõneks ajaks said keelekorralduses määravaks üksikisikud, näiteks Ernst Nurm, ent natuke vabamate aegade tulles 1950 . aastate lõpus pöörduti tagasi kollektiivse keelekorraldusorgani poole. 1960. aastal moodustas Eesti NSV Ministrite Nõukogu vabariikliku õigekeelsuskomisjoni, mis sai tuttavaks lühendi VÕK all. See oli ka ainus kord, kui riigivõim moodustas keelekorraldusorgani. Tuleb tunnistada, et väga bürokraatlikult moodustatud kogu ei hakanudki korralikult tööle ning pärast 1965 . aastat sisulist tööd ei tehtud. Tööle hakkas hoopis VÕK-i teine koosseis, mille moodustas seekord juba teaduste akadeemia 1972. aastal ning mis tegi mitu otsust morfoloogia ja nt nimekirjutuse kohta. Vahepealsel ajal, kui VÕK ei toiminud, tegutses Emakeele Seltsi keeletoimkond (1969-1972), kelle tähtsündmuseks sai 1972. aastal toimunud uute sõnade võistlus, mis tõi käibele sõnad kohuke, pardel, linnak jms. Kõige tulemuslikumaks on Tiiu Erelt pidanud VÕK-i kolmanda koosseisu tööd (moodustati 1979, tegutses aktiivselt kuni 1983. aastani, paberi peal veel aastani 1997). Selle ajal tehti palju morfoloogiaotsuseid (muuseumtüübi, kõnelema-tüübi kohta jne) ning õigekirjaotsuseid, sh uus lühendireeglistik, kokku- ja lahkukirjutus jne.

Vaba riigi taas tekkides ei sobitunud vabariiklik õigekeelsuskomisjon uutesse oludesse enam hästi, mh oma nimetuse tõttu, ja seepärast on pöördutud tagasi keeletoimkonna, täpsemalt Emakeele Seltsi keeletoimkonna nimetuse juurde. Toimkond moodustati 1993. aastal ja tegutseb tänini, keeletoimkonna vanema valib iga kahe aasta tagant ES-i üldkoosolek, praegu on vanem Maire
Raadik. Kuigi riik tegevusse ei sekku, on erinevalt sõjaeelsest Eestist praegu kirjakeele norm määratud keeleseadusega ja kirjakeele normi rakendamise korraga.

Vaadakem otsa ka ÕS-ide pikale reale. Nagu öeldud, sai 1918. aasta „Eesti keele õigekirjutuse-sõnaraamat" kohe otsa ja Eesti Kirjanduse Selts hakkas koostama selle teist trükki, mis aga paisus mahult mitmeks köiteks. 1925. aastal ilmus I köide, mille puhul Johannes Aavik rõõmustas, et keeleuuendusest on paljugi omaks võetud, kuigi mitte piisavalt. II köide ilmus 1930 ja III köide 1937, kavandatud lisadega IV köide jäigi ilmumata. Selle pika aja jooksul oli I köide juba osalt vananenud ning praktiliseks abivahendiks sai hoopis Elmar Muugi „Väike õigekeelsus-sõnaraamat”, mille esimene trükk ilmus 1933 ja millest peaaegu igal aastal ilmus uus, parandatud trükk kuni aastani 1946. Nõukogude ajal alustati 1948 „Suure õigekeelsusesõnaraamatu" koostamist, mis jäi pooleli, 1953. aastal ilmus nõukogulike põhimõtete järgi koostatud „Väike õigekeelsuse sõnaraamat" ning järgnevalt on õigekeelsussõnaraamatud, natuke erinevate pealkirjade all, ilmunud 1960, 1976, 1999, 2006 ja 2013. Sügisel 2018 ilmus ÕS-ide saja aasta tähistamiseks uus ÕS koos oma sajandivanuse paarilisega, mis annab ühtlasi võimaluse vaadelda kirjakeele normi muutumist saja aasta jooksul.

Selline on vormiline tagasivaade sajandi keelekorraldusele, ent milline on olnud keelekorralduse sisuline tähendus selle aja jooksul? Kuidas on ühiskond sellesse suhtunud? Siin tuleb paratamatult natuke meelevaldselt üldistada, kuid mulle näib, et sõjaeelses Eestis suhtuti keelekorraldusse entusiasmiga - eesti keel oli ju riigikeelena algaja ja kõike peeti võimalikuks. Vaieldi tuliselt ning mõnikord pälviti ka ajakirjanduse pilkavat tähelepanu - nagu Aaviku sõjas sõna uulits vastu -, kuid üle kõige lehvis vaba vaim, mis lubas ametlikesse normidesse suhtuda ka paindlikult. Palju 
on kuuldud Johannes Aaviku kirglikust keeleuuendusest ja sellele vastanduvast J. V. Veski keelekorraldusest (siin on see sõna kitsamas tähenduses), kuid see näib olevat hiljem belletristlikult suureks puhutud vastandus. Tegelikkus oli kirevam, ka Aavik järgis nt koolide inspektorina ametliku keele norme, kuigi tal oli eriarvamusi, ja J. V. Veski mõnda uudissõna võiks ka Aaviku omadega võrrelda. Elmar Muuk seekõrval oli praktilise meelega keelekorraldaja, kes püüdis eri suundi ühendada, aga kõige enam jälgis ta tegelikku pruuki, jõudes seega päris lähedale tänapäevasele vaatele.

Ent poliitilised olud muutusid ja uutes, nõukogude korra viljastavates tingimustes kumas oht juba keelele endale. Seetõttu sai keelekorraldusele ja täpsemalt praktilisele keelehooldele omaseks kaitseseisundile tüüpiline hoiak: võideldi võõrmõjude vastu. Ajastule omane jäikus tingis ka keelekorralduse jäikuse, kohati tigedaltki võideldi kas keele rahvalikkuse säilitamise nimel või teadusliku lähenemise kaitseks ning vaidlused olid - selle aja kõnepruuki kasutades printsipiaalsed. Keelekorraldajad tajusid neile antud suurt võimu keele üle ja tegutsesid vastavalt. Ühiskond vaatas neile kui autoriteetidele ja ootas neilt eeskätt keeleasjade paikapanekut. Avalik kritiseerimine ei tulnud kõne alla.

Mõistagi on see lihtsustus ja keelekorralduski teisenes aja jooksul natuke ühiskonnast erinevalt. Eriti ilmnes see 1970. aastate teisel poolel, kui olid taastunud kontaktid Soomega ja tegutsema asus keelekorraldajate uus põlvkond. Keeleelu elavnes 1970. aastatel lausa erandlikult, 1972. aasta sõnavõistlus lõi selleks soodsa fooni; ilmus palju keeleteemalisi raamatuid. Keelekorraldus muutus jälle kritiseeritavaks, mis tähendas vähemalt keeleküsimuste osas ühiskonnas vaba arutelu. Mulle tundub, et selle vabaduse kasutamisega kompenseeriti poliitiliste vabaduste puudumist. Toon näiteks kas või võõrnimede kirjutuse üle vaidlemise. Kui kunagi uurisin nende vaidluste ajalugu, siis algul imestasin väga, et 1920.-1930. aastatel ei olnud nii kirglikke vaidlusi kui näiteks 1980-ndatel, kui VÕK tegi oma otsuse maade ja pealinnade nimede kirjutamise kohta. Ma enam ei imestanud, kui kätte jõudsid 1990. aastad ning võorrnimede teema vajus jälle kuhugi hämariku piirile, see ei erutanud enam murdosagi neist, kes nüüd ei pidanud enam asendustegevusega tegelema, vaid võisid end välja elada näiteks poliitikas.

Jõuamegi tänasesse päeva ja mulle tundub, et kohati me elame endiselt üleminekuajas. Me peaksime keelekorraldust võtma kui praktilist tegevust keele funktsionaalsuse tagamiseks, suhtuma sellesse paindlikult, teadvustama, et keelekorraldus ei ole kõikvõimas, vaid üksnes soovitav, nõuandev ja mõnikord ka suunav. Paljude eestlaste ihalus rangete normide järele või ideaalkeele taotlus on jäänud silma ka väljaspool Eestit, nagu näitab alguses esitatud Robert $\mathrm{T}$. Harmsi tsitaat. ${ }^{6}$ Keelekorraldus taandus käskimiselt-keelamiselt juba 1970. aastatel; tasapisi on otsuseid hakatud nimetama soovitusteks, sest vabas ühiskonnas ei saa inimesi käskida, ning tundub, et edaspidi võiks soovituste asemel või kõrval rääkida ka normi kirjeldamisest, st keelekorraldajate ülesandeks saab suurel määral kirjeldada seda, mis kogutud andmete põhjal on ühiskonnas kujunenud keelenormiks.

Tunnustatud arusaama järgi on kaht liiki norme: objektiivne keelenorm, mis mingis keeleühiskonnas vaikimisi kehtib, ja normingud, mida annavad autoriteetsed kogud näiteks mingite üksikküsimuste reeglistamiseks. Vahel on neid nimetatud normiks A ja normiks B ning mõni keelekorraldaja, nt Henn Saari, on defineerinud ka normi C, ideaalkeele, mille suunas liikuda soovitakse. Keelenormi kirjeldus märgibki seda, et püütakse kindlaks teha objektiivne norm ja kasutajaid sellest infor-

${ }^{6}$ Robert T. Harmsi tähelepanekud Eesti oludest võivad jääda küll pigem Nõukogude aega. 
meerida. Alati ei ole see muidugi võimalik, sest keelekasutajad on eri tausta ja huvidega ja ühtset normi siis pole.

Keelekorralduse enda teisenemise kohta võib ehk üldistada nii, et algusaegade vahel heitlikud üksikküsimuste otsused on hiljem arenenud süsteemsemate muutuste tunnustamiseni, eriti puudutab see morfoloogiat. Ja üha enam on tuginetud keelekasutuse uurimise tulemustele.

On kaks vaikimisi eeldust, mida on läbi aegade silmas peetud: 1) senised normingud jäävad uute normingute kõrval samuti õigeks; 2) kirjakeele ehk standardkeele ning „tegeliku” keele vahe ei tohi kujuneda liiga suureks. Tõsi, me oleme olukorras, kus kirjakeele mõiste on kasutajate teadvuses hägustunud. Kirjakeel terminina ei tähenda kindlasti sama mis kirjutatud keel, tänapäeval on meie ümber teksti väga palju ja sellest suur osa ei ole kirjakeel ehk normikeel ehk standardkeel. Keelekasutajal tuleb valida, mis olukorras ta üldse kirjakeelt vajab. Ning ühiskond peab kokku leppima, millises olukorras kirjakeele kasutamist eeldatakse.

Keelekorralduse põhiülesandeks võiks tänapäeval olla seista vastu keele vaesumisele, selgitada keelekasutajale keele rikkusi ja õpetada neid teadlikult kasutama.

Keelekorraldus tugineb $\mathrm{ka}$ vabas ühiskonnas autoriteedile ja mõni seisukoht paistab dogmana. Nagu sõjanduses on täheldatud, et võideldakse mineviku sõdu, nii ka keelekorralduses võideldakse vahel keelejoontega, mida on pikalt taunitud, kuid mis sellest hoolimata ei taandu. Vahel võib õigustatult küsida: kaua veel?

Rääkides keelekorraldaja rollist tänapäeva ühiskonnas, tundub mulle, et edukas keelekorraldaja peaks olema ühtlasi suhtekorraldaja, kes peab kannatlikult oma vaateid ja ettepanekuid selgitama ning hoolitsema ühtlasi selle eest, et sellele kõigele ei riputataks külge mõnda naeruväärset silti, nagu juhtus poolteist aastakümmet tagasi, kui muidu asjalik ülevaade ilmus ajalehes pealkirja all „Keelefüürerite käsud ja keelud”. Tänapäeva sildistamishimuline ajakirjandus paneb vähegi tõsisema keelekorraldaja muretsema libastumisohu pärast ja kui oled sildi külge saanud, siis see jääb internetti igaveseks. Teisalt, kui ise sõna ei võta, siis täidavad selle ruumi teised „arvajad”, kes kinnistavad keelekorralduse kohta kujunenud stereotüüpe, näiteks et nüüd on kõik vabaks antud, reegleid polegi.

Üks raske teema on see, et ühiskond on vastandlike huvidega. Lihtsad mustvalged reeglid oleksid head kooliõpetuses ja neist on huvitatud ka keeletoimetajad, kes kõiki keelekorraldajate soovitusi rakendavad imetlusväärse innuga. Keelereegleid aga ei õnnestu peaaegu kunagi mustvalgeks sõnastada, ikka jääb piiripealseid asju. Näiteks on keeletoimkond otsustanud edaspidi mitte tõmmata kujundlike koha- ja isikunimede algustähe puhul piiri (sellised nagu Uus Maailm, Must Mander, tõusva päikese maa, igavene juut) ja jätta keeletarvitaja otsustada, kas ta peab seda nimeks või mitte. Senine esitus jättis mulje, nagu oleks meil sahtlis mingi nimekiri, mille põhjal otsustada, ent niisugust pole kunagi olnud. Kindlasti on neid, keda see häirib.

Keelekorraldus peab kokku sobima ühiskonnaga ja kui see on demokraatlik, siis ei saa keelekorraldus olla autoritaarne. Paljud muidu sümpaatsed mõtted, mida keelekasutuse kohta sageli esitatakse, on sümpaatsed niikaua, kuni ei peeta silmas nende ellurakendamist. Viimane eeldab sageli hoopis teistsugust ühiskonda, mis ei ole nii sümpaatne, nt sisaldab tsensuuri.

Sajandile tagasi vaadates mõelgem eesti kirjakeelele kui aja- ja kultuuriloolisele varandusele, keele esinduskujule, mis on mitme põlvkonna kokku kantud ja mis on väärt, et seda edasi arendada. 